Voix et Images

volxetimages

\title{
Index du volume XXXVIII
}

Volume 39, numéro 1 (115), automne 2013

URI : https://id.erudit.org/iderudit/1023003ar

DOI : https://doi.org/10.7202/1023003ar

Aller au sommaire du numéro

Éditeur(s)

Université du Québec à Montréal

ISSN

0318-9201 (imprimé)

1705-933X (numérique)

Découvrir la revue

Citer ce document

(2013). Index du volume XXXVIII. Voix et Images, 39(1), 185-186.

https://doi.org/10.7202/1023003ar

Ce document est protégé par la loi sur le droit d'auteur. L'utilisation des services d'Érudit (y compris la reproduction) est assujettie à sa politique d'utilisation que vous pouvez consulter en ligne.

https://apropos.erudit.org/fr/usagers/politique-dutilisation/
Cet article est diffusé et préservé par Érudit.

Érudit est un consortium interuniversitaire sans but lucratif composé de l’Université de Montréal, l'Université Laval et l'Université du Québec à Montréal. Il a pour mission la promotion et la valorisation de la recherche. https://www.erudit.org/fr/ 


\section{INDEX D U VOLUME XXXVIII}

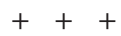

AQUIN, Hubert, «Édition génétique d'Odyssée américaine (extraits)», 1, p. $21-25$

BÉRARD, Cassie, «Narrateur à l'action. Étude de la nouvelle "Elles détestaient Madrid" de Guillaume Corbeil», 1, p. 111-122.

BONENFANT, Luc, «Se préfacer, dans l'oubli de soi-même», 2 , p. 33-47.

BRASSARD, Denise, «Objets de fascination", 1, p. 135-143.

BRASSARD, Denise, "Quand tout s'emmêle", 2, p. 138-145.

BROCHU, André, «Le souffle du Noroît», 1, p. 144-149.

BROCHU, André, «Fin de trilogie», 2, p. 146-151.

BROCHU, André, «Petit spécial "Les Herbes rouges" », 3, p. 147-152.

CHABOT, Julien-Bernard, «Portrait de Réjean Ducharme en messie des lettres québécoises», 2, p. 93-109.
CONSTANT, Marie-Hélène, «De la judéité souterraine au texte-crypte dans Barney's Version de Mordecai Richler», 3, p. 113-126.

CUSSON, Marie, «L'absence du père dans "Relation" de Michael Delisle», 3, p. 75-85.

DELISLE, Michael, «Inédit. Éléments de poésie [extraits]», 3, p. 25-29.

\section{GODBOUT, Patricia, «La franco-} américanité de Louis Dantin vue à travers son amitié littéraire avec Marine Leland», 2, p. 49-58.

HAMEL, Jean-François, «Politiques de Saturne. La mélancolie d'Hamlet chez Jacques Ferron et Hubert Aquin», 1, p. 85-99.

HAYWARD, Annette (pour l'établissement du texte), «Inédit. Lettre de Louis Dantin à Germain Beaulieu», 2, p. 11-16.

HAYWARD, Annette, «Louis Dantin et l'écriture autobiographique», 2, p. 17-32.
INKEL, Stéphane, «Un témoin dérangeant. À propos de Pierre Vadeboncœur»", 2, p. 125-131.

INKEL, Stéphane, « Géographies littêraires», 3, p. 129-135.

JAROSZ, Krzysztof, « Jadis et maintenant», 3, p. 136-140.

JOUBERT, Lucie, «"Femmes exceptionnelles: des exceptions à quelle règle?" Nouveaux regards sur l'histoire littéraire des femmes ", 1 , p. $150-155$

KIROUAC-MASSICOTTE, Isabelle, "Les débuts diaristiques d'Hubert Aquin », 1, p. 13-19.

KIROUAC-MASSICOTTE, Isabelle, «Bibliographie d'Hubert Aquin. Mise à jour 1997-2012», 1, p. 101-107.

LACROIX, Michel, «Dantin et l'âge de la métacritique : école, amitié et dissensus», 2, p. 73-89.

LAFOREST, Daniel, «Le Lascaux Mont-Royal de Normand de 
Bellefeuille et la honte du passé québécois», 2, p. 111-121.

LAFOREST, Daniel et Michel NAREAU, «Transitions et passages dans l'œuvre de Michael Delisle», 3, p. 7-10.

LAFOREST, Daniel et Michel NAREAU, «Entretien avec Michael Delisle», 3, p. 13-23.

LAPOINTE, Martine-Emmanuelle, «Mort et renaissance de l'écrivain maudit. Lectures de l'œuvre et de la figure d'Hubert Aquin dans l'essai québécois contemporain », 1, p. 2741.

LAPOINTE, Martine-Emmanuelle, " "Ailleurs improbables"», 1, p. 125128.

LAPOINTE, Martine-Emmanuelle, «Géométries variables», 2, p. 132137.
LEE MUMM, Shanna, «Bibliographie de Michael Delisle», 3, p. 101-108.

LEPAGE, Élise, «"Faire avec ce qu'il y $a^{\prime \prime}$ : l'humilité du poème chez Michael Delisle», 3, p. 31-45.

MARTEL, Jacinthe et Jean-Christian PLEAU, «Relectures d'Hubert

Aquin», 1, p. 7-10.

MAVRIKAKIS, Catherine, «Arrêt sur quelques images de l'enfance », 3, p. 47-57.

MORENCY, Jean, «Louis Dantin, écrivain polygraphe», 2, p. 7-10.

MORENCY, Jean, "Les enfances de Fanny: un roman américain ", 2, p. 59-71.

MOTTET, Philippe, «La Bildung dans quatre nouvelles du Sort de Fille de Michael Delisle», 3, p. 59-73.
NAREAU, Michel, «Entre Ducharme et le Mexique: fragilité des transitions culturelles dans Drame privé de Michael Delisle», 3, p. 87100.

PLEAU, Jean-Christian, « Le zâr taciturne: Jean-William Forestier ", 1, p. 73-84.

RANDALL, Marilyn, «Le roman en perspective curieuse. Trou de mémoire et l'anamorphose (de la mort) de l'auteur», 1, p. 59-72.

RIENDEAU, Pascal, «Quelle Amérique?», 1, p. 129-134.

RIENDEAU, Pascal, «Nouvelles voix romanesques», 3, p. 141-146.

SAINT-GELAIS, Richard, «Derniers épisodes. Quelques lectures récentes de Prochain épisode», 1, p. 43-57. 